Chapter 4

\title{
Integration of Farm Fossil Fuel Use with Local Scale Assessments of Biofuel Feedstock Production in Canada
}

\author{
J.A. Dyer, R.L. Desjardins, B.G. McConkey, \\ S. Kulshreshtha and X.P.C. Vergé \\ Additional information is available at the end of the chapter \\ http://dx.doi.org/10.5772/52488
}

\section{Introduction}

The viability of Canadian biofuel industries will depend on farm energy consumption rates and the $\mathrm{CO}_{2}$ emissions from fossil fuel use for feedstock crops. The types of biofuels that are under development in Canada include biodiesel, grain ethanol, cellulosic ethanol and biomass. Each of these fuels relies on a distinct class of feedstock crops and in each case the most suitable crop is also dependent on geographic location. For example, the feedstock for biodiesel is canola in Western Canada and soybeans in Eastern Canada (Dyer et al., 2010a). For grain ethanol, the feedstock choices are corn in the east and wheat in the west (Klein and LeRoy, 2007). Cellulosic ethanol is still under development in Canada.

Technological changes in ethanol manufacturing can bring about different intensities of land use and require different land capabilities. Cellulosic ethanol and biomass can make use of land not capable of growing grains, and can exploit part of the straw from annual field crops (Dyer et al., 2011a). As a result, impacts on other land use activities with which feedstock crops compete also depend on the particular feedstock involved in the interaction and the capability of the land. Impacts on the overall sustainability of agriculture are minimal when management practices fit the local environment (Vergé et al., 2011). Therefore, to understand the different comparative advantages and impacts among regions, each landscape requires its own assessment.

Two main principles must guide biofuel industries. The first is that they must produce more energy than the fossil energy used for their production. The second is that they must displace more Greenhouse Gas (GHG) emissions than are released during their production 
(Dyer and Desjardins, 2009; Klein and LeRoy, 2007). Biofuels appeal to governments for the potential to create economic opportunities in rural areas (Klein and LeRoy, 2007). Due to transport costs, feedstock crops are best grown on land that is close to facilities for processing them into biofuel. Thus, it is important to have objective criteria for determining which communities and regions are the most suitable locations for those processing plants. In addition, sustainable feedstock production requires that local suitability be established (Dyer et al., 2011a; Vergé et al., 2011). To date, a comprehensive farm energy analysis has not been done at a local scale in Canada.

The main goal of this chapter was to determine the geographic distribution of farm energy terms within each province of Canada. Due to their small sizes and limited role in Canadian agriculture, the four Atlantic Provinces were treated as one combined province. A secondary goal of this chapter was to demonstrate how much the farm energy budget contributes to the GHG emissions budget of the agricultural sector through fossil $\mathrm{CO}_{2}$ emissions at a provincial scale. Using area based intensity, a simple demonstration was also provided of how these data could provide a baseline comparison for the fossil $\mathrm{CO}_{2}$ emitted from growing a grain ethanol feedstock compared to current types of farms. These goals were achieved through the integration of existing models and databases, rather than by analysis of new data collected specifically for this purpose.

\section{Background}

The feedstock for biofuels has raised several land use questions (GAO, 2009; Malcolm and Aillery, 2009). These include: How much land will biofuel feedstock production require in order for biofuels to make an appreciable contribution to energy supply? What agricultural products would be displaced to accommodate this production? How will food supply be threatened by feedstock production? How much will meat production and livestock industries be displaced by feedstock? In large part, most of these general land use policy questions have been addressed in Canada and elsewhere. However, there have been some shortcomings of these analyses.

One of these gaps is the failure by many studies to account for carbon dioxide $\left(\mathrm{CO}_{2}\right)$ emissions caused by fossil fuel use in the feedstock production, and in agriculture, generally. One of the reasons for this gap is that under the United Nations Framework Convention on Climate Change, emissions from fossil fuels used for agriculture are reported as part of the energy sector, rather than under the agriculture sector. Although smaller in magnitude than both the methane $\left(\mathrm{CH}_{4}\right)$ and nitrous oxide $\left(\mathrm{N}_{2} \mathrm{O}\right)$ emissions reported for agriculture, farm energy-related $\mathrm{CO}_{2}$ emissions are an important component of the sector's GHG emissions budget, largely because it is manageable (Dyer and Desjardins, 2009). For example, reduced tillage practices which diminish fossil fuel $\mathrm{CO}_{2}$ emissions from farm machinery (Dyer and Desjardins, 2003a), as well as conserving soil carbon, can be the difference in whether a particular feedstock or its biofuel are energy-positive or a sink for GHGs. 
Without taking all forms of fossil energy use in agriculture into account, the GHG emissions budget for crop production is incomplete. In addition to farm field operations, the fossil fuel $\mathrm{CO}_{2}$ emissions include agro-chemical manufacturing, equipment manufacturing, fuels for grain drying or heating farm buildings, gasoline, and electricity for lighting or cooling (Dyer and Desjardins, 2009). However, farm field operations are the most complex term and have the greatest degree of interaction with land features and crop choices. Fossil fuel consumption for farm field work has been computed using the Farm Field work and Fossil Fuel Energy and Emissions (F4E2) model (Dyer and Desjardins, 2003b; 2005). Because of their dominant role in defining regional differences in fossil fuel energy and $\mathrm{CO}_{2}$ emissions, farm field operations have already been assessed in more detail than other farm energy terms (Dyer et al., 2010b).

\section{Methodology}

\subsection{Selecting the spatial scale}

Since decision making in the biofuel industries is limited by spatial scale, assessing the most appropriate scale was the first task undertaken in this analysis. Disaggregation of the Canadian farm energy budget to the provinces can exploit agricultural statistics available at two spatial scales. The first scale is the Census Agricultural Regions (CAR) (Statistics Canada, 2007), while the second scale is at the Soil Landscapes of Canada (SLC) (AAFC, 2011). Due to its association with agricultural census records, the geographic scale chosen for distributing farm energy use in this chapter was the CAR system which divides Canada into 55 regions (with each of the Atlantic Provinces treated as a single CAR). In spite of the soil and land variables available for SLCs, some difficult assumptions are needed to disaggregate some data to this scale. In addition to this uncertainty, the large number of spatial units in Canada at the SLC scale (nearly 4,000 units having agriculture) made presentation on the basis of SLCs impractical for this chapter.

The CARs are identified in this chapter by numbers that start from 1 in each province. In the Atlantic Provinces, with each province treated as one CAR. Hence, CAR numbers 1, 2, 3, and 4 represent New Brunswick, Prince Edward Island, Nova Scotia and Newfoundland, respectively. With the agricultural regions of Canada being spread out largely east to west, it was not practical to display the boundaries on a single page map. So, a website location, rather than a printed map, was provided in this chapter. To view the CAR sizes and locations in each province, visit: http://www.statcan.gc.ca/ca-ra2011/110006-eng.htm.

\subsection{Farm energy budget}

The six terms in the farm energy budget adopted for this analysis were those defined by Dyer and Desjardins (2009). All of these terms reflect operational and/or financial decisions made by farmers. For example, the energy costs of transporting products from farm gate to market that are paid for by the processer or marketer, rather than the farmer, were excluded. These terms involved several different types of fossil fuel. Based on the analytical methodol- 
ogies required for spatial disaggregation, these six terms were separated into three groups. The diesel fuel used in farm field work (Dyer and Desjardins, 2003b; 2005) and the coal required to manufacture and supply farm machinery (Dyer and Desjardins, 2006a) were the first group because they were both quantified with the F4E2 model.

The fossil energy to supply chemical fertilizers and pesticide sprays was determined from a direct conversion of the weight of consumption of these chemicals (Dyer and Desjardins, 2007). Since nitrogen fertilizers are the most energy-intensive chemical inputs to manufacture, and have available sales records in Canada, this conversion was based on the natural gas to manufacture just nitrogen fertilizer. The energy conversion rate of $71.3 \mathrm{GJ} / \mathrm{t}\{\mathrm{N}\}$ derived from Nagy (2001) as an average for five census years from 1981 to 2001 was used in this chapter. Although this conversion was for just nitrogen supply, it was indexed to include other farm chemicals, mainly phosphate and potash fertilizers.

The third group includes electrical power, gasoline and heating fuels. All three terms in this group had to be determined empirically since there was little basis for modeling these terms. While to some extent diesel is increasingly being used for farm owned transport vehicles, in 1996 the F4E2 model accounted for all but a small percentage (Dyer and Desjardins, 2003b; 2005) of the farm-purchased diesel fuel for farm field work. Only one percent of this diesel fuel was for household use in 1996 (Tremblay, 2000). This suggests that pick-up trucks, the sort of vehicle that would be used for both light haul farm transport and family business, were not typically diesel powered in 1996. Therefore, gasoline, rather than diesel, was likely the main fuel used for farm owned transport vehicles in 1996, the baseline year for the farm energy budget described by Dyer and Desjardins (2009). There was, therefore, no justification for including any diesel fuel in the third group of energy terms. In keeping with the conditions of the farm energy budget described above, any diesel fuel consumed by commercial trucks used for hauling grain and livestock to market or processing were not considered in this analysis.

Electrical power was a partial exception to the need for empirical determination because of a semi-empirical index of the $\mathrm{CO}_{2}$ emissions from this term based on farm types (Dyer and Desjardins, 2006b). This index demonstrated the correlation, at least for this energy term, between energy consumption and farm types, particularly among livestock farms. Application of this index for this analysis was unnecessary because in this case livestock populations are only needed to distribute a known quantity of electrical energy among provinces and regions (CARs).

The most comprehensive source of farm energy use information in Canada is the 1996 Farm Energy Use Survey (FEUS) of Canada (Tremblay, 2000). The FEUS provided commodityspecific estimates for the three energy terms for which detailed modeling algorithms were not available. Given this empirical source, for example, it did not matter whether all gasoline was burned in farm owned transport vehicles or whether all such vehicles were powered by gasoline. What mattered was that the FEUS provided an empirical quantity of gasoline that had to be disaggregated regionally. The remaining term in the Canadian farm energy budget was a combination of three fuels, including furnace-oil, liquid propane (LPG) and natural gas, which was defined by Dyer and Desjardins (2009) as heating fuels. 


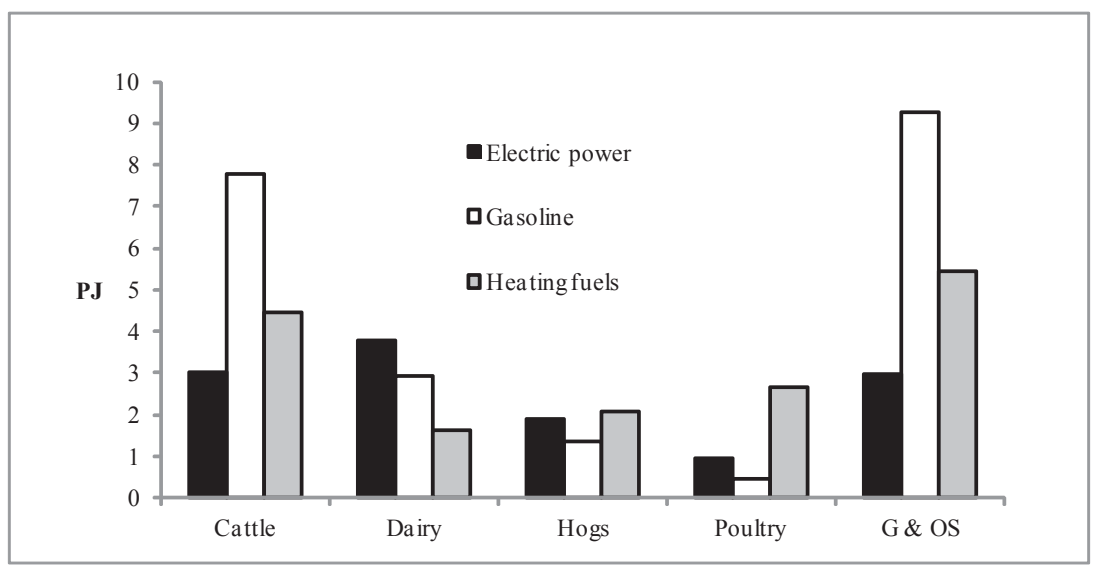

Figure 1. National consumption of three types of energy by five farm types identified in the 1996 Farm Energy Use Survey (FEUS) of Canada.

Due to confidentiality constraints, the FEUS data were not directly available at the farm level. The FEUS, however, did allow energy type data to be grouped by farm type, but only for Canada as a whole. While energy types were also grouped by provinces in the FEUS, this breakdown could not be linked to farm type uses. The FEUS also gave the consumption of diesel fuel in Canadian agriculture which was used to verify the F4E2 model (Dyer and Desjardins, 2003b). The quantities for the farm energy terms extracted from the FEUS, shown in Figure 1, illustrate the range in energy quantities that had to be disaggregated for these three energy types. These energy data were adjusted for the shares of these fuels that were used in farm households instead of farm use. These household share adjustments were only provided by fuel type, however, and not for farm type (Tremblay, 2000).

Although the purpose of the data in Figure 1 was not to compare farm types, these energy quantities still reflect both the different sizes and energy intensities of these farming systems in Canada. Grain and oilseed farms accounted for 35\% of the consumption of these three energy terms. The range of total live weights in Canada for beef, dairy, hogs and poultry of 5.7, 1.1, 0.8 and 0.2 Mt, respectively, during 2001 (Vergé et al., 2012) was wider than the range in uses of these three energy types among the four livestock industries seen in Figure 1. Hence, while beef production used the largest share of this energy of any of the livestock industries, beef farms were the least intensive user on a live weight basis. Similarly, poultry, the smallest livestock industry and lowest user of these energy terms, was the most intensive user of these three types of energy.

\subsection{Land use}

In defining the GHG emission budgets for each of the Canada's four dominant types of livestock production, dairy, beef, pork and poultry, Vergé et al. (2007; 2008; 2009 a,b) took into consideration the land base on which the feed grains (including oilseed meal) and forage 
that support livestock are grown. Vergé et al. (2007) recognized that the carbon footprint for each livestock industry must include the land base that supports the crops in the livestock diet. Subsequently, the total area involved in Canadian livestock production was defined as the Livestock Crop Complex (LCC). The LCC was based on an array of crops that defined the diets of all four livestock types, including barley, grain corn, soybean meal, feed quality wheat, oats, canola meal, dry peas, seeded pasture, alfalfa, grass hay and silage corn.

The Canadian Economic and Emissions Model for Agriculture (CEEMA) was developed to estimate the spatial distribution and magnitude of GHG emissions generated by the agriculture sector (Kulshreshtha et al., 2000). Because the spatial unit of CEEMA was the CAR, this model was well suited for the analysis described in this chapter. CEEMA is composed of records of crop areas, yields, nitrogen fertilizer rates and related GHG emissions during 2001 for all field crops in each CAR. Almost 1,900 of these crop records were distributed over 55 CARs in CEEMA. While crop records identify the CAR in which they lie and define the areas of all crops within each CAR, the actual locations of crops described in the respective records within the CAR are not specified. Another limitation of the CEEMA was that these crop records were generated from analysis of optimal economic land uses for 2001 (Horner et al., 1992; Kulshreshtha et al., 2000), rather than from actual crop statistics.

The variables that determine differences among the CARs are related primarily to land use differences and farm level decisions. These variables include the selections of crops, particularly those crops that feed livestock. The CEEMA crop records do not contain soil type data. Livestock populations at the CAR scale were also not available for this analysis to preserve the confidentiality of the farmers surveyed at that scale. The variables required for assessing farm energy at the CAR scale will be discussed in more detail below.

Estimates of GHG emissions from Canada's four main livestock industries were integrated with the CEEMA. The area of each crop that was in the LCC from each CAR in each province was determined as part of a previous application of CEEMA (Dyer et al., 2011b). That study disaggregated the LCC to each crop record describing crops in the diet of Canada's four main livestock types. Some feedstock-food-livestock interactions on a national or provincial scale in Canada were analyzed in that study. It also used the CEEMA database to separate Canadian farmland into land that supported livestock and land available for other crops. However, Dyer et al. (2011b) did not separate these emissions by livestock type. Farm energy consumption and fossil fuel $\mathrm{CO}_{2}$ emissions for farm field work have been disaggregated at a provincial scale (Dyer et al., 2010b). But no other farm energy terms have been disaggregated at a scale that allows the full farm energy budget to be quantified in the CARs.

\subsection{Farm energy and livestock distributions}

For the three energy terms that can only be treated empirically, electric power, gasoline and heating fuels, the FEUS provided the only link to farm types. Because of the availability of provincial livestock population data from the Canadian agricultural census, this disaggregation can be done directly at the provincial scale. Grain and oilseed production, which was defined as a farm type in the FEUS, accounted for part of each of these three energy terms. 
Therefore, provincial summaries of areas in these crops were also involved in the disaggregation process.

These farm type links meant that disaggregation of these energy terms to the CAR scale could be achieved through correlation with livestock populations and crop areas. The underlying assumption was that most farm animals are located near their feed sources. This assumption was required because information on where in the provinces farm animals are actually housed was not available for this analysis (Tremblay, 2000). This limitation only affected the three empirical energy terms, including electric power needs, heating fuels and gasoline for farm transport. The farm field work and the two input supply terms can be linked directly to the CARs through CEEMA, as well as to the provinces.

Provincial estimates had to be generated for all three energy terms taken directly from the FEUS. To achieve this, the relative distribution of energy quantities across the provinces was determined for each farm type identified in the FEUS. To quantify each livestock farming system, the inter-provincial distribution was determined on the basis of the total weight of all live animals in all age-gender categories in the livestock type. The provincial live weight was calculated from the average live weight $(\mathrm{W})$ of each age-gender category $(k)$ of each livestock type $(a)$ and the number of head $(\mathrm{H})$ in each age-gender category and livestock type. The amount of energy from each energy term for each of the livestock systems from the FEUS $\left(\mathrm{E}_{F E U S, a}\right)$ was disaggregated to the provincial energy quantity $\left(\mathrm{E}_{\text {prov }}\right.$ ) by the respective shares of live weight in each province (prov), as follows.

$$
\mathrm{E}_{\text {prov }, \mathrm{a}}=\mathrm{E}_{\mathrm{FEUS}, \mathrm{a}} \times\left(\sum^{\mathrm{k}} \mathrm{W}_{\mathrm{k}, \mathrm{a}} \times \mathrm{H}_{\mathrm{k}, \text { prov }, \mathrm{a}}\right) /\left(\sum^{\text {Canada }} \sum^{\mathrm{k}} \mathrm{W}_{\mathrm{k}, \mathrm{a}} \times \mathrm{H}_{\mathrm{k}, \text { prov }, \mathrm{a}}\right)
$$

The disaggregation of these energy terms for the farms that produce grains and oilseeds to the provinces was similar to Equation 1 . The difference was that live weights $(\mathrm{W} \times \mathrm{H})$ were replaced by the provincial crop areas in this farming system. The areas of each grain and oilseed crop were summed over the crop records of grain or oilseed areas in the CEEMA database. The first sum was for the crop records in each CAR to determine CAR area totals. The provincial totals for each type of grain or oilseed crop were then estimated from the sum of all areas in that crop type over all CARs in each province. This summing process was only applied to the actual grains and oilseeds crops. So rather than correlate the entire area in these crops with the energy terms, differences between these area totals and the areas of these annual crops in the LCC were used. Dyer et al. (2011b) defined these areas as the NonLivestock Residual areas (NLR). The provincial quantities for the three energy terms and the five farm types shown in Figure 1 are given in Table 1.

A simpler computational sequence was used for the two energy terms derived from the F4E2 model and the energy term for chemical inputs. This was possible because the data for calculating these terms could be taken directly from the crop records of the CEEMA database. The main input variable from CEEMA for the F4E2 calculations was crop areas, whereas total chemical nitrogen applications were available in all CEEMA crop records for the chemical input supply energy term. Because these two energy terms were calculated on each 
crop record, they could be summed directly from the CEEMA database. While the calculations for grains and oilseeds used only the records for those crops designated as grains and oilseeds, calculations for these three terms used all crop records associated with the LCC or NLR. The F4E2 model took into account whether the crops were annual grains or perennial forages, along with the yields of each crop (Dyer and Desjardins, 2005).

\begin{tabular}{|c|c|c|c|c|c|}
\hline & Beef & Dairy & Hogs & Poultry & ${\mathrm{G} \& O S^{2}}^{2}$ \\
\hline & \multicolumn{5}{|c|}{ PJ } \\
\hline & \multicolumn{5}{|c|}{ Electric power } \\
\hline British Columbia & 0.15 & 0.25 & 0.02 & 0.14 & 0.00 \\
\hline Alberta & 1.71 & 0.26 & 0.32 & 0.10 & 0.75 \\
\hline Saskatchewan & 0.59 & 0.10 & 0.22 & 0.04 & 1.60 \\
\hline Manitoba & 0.33 & 0.13 & 0.48 & 0.07 & 0.35 \\
\hline Ontario & 0.27 & 1.28 & 0.58 & 0.40 & 0.06 \\
\hline Quebec & 0.12 & 1.20 & 0.70 & 0.26 & 0.02 \\
\hline Atlantic & 0.03 & 0.20 & 0.06 & 0.06 & 0.01 \\
\hline \multirow[t]{2}{*}{ Canada } & 3.20 & 3.42 & 2.40 & 1.07 & 2.78 \\
\hline & \multicolumn{5}{|c|}{ Gasoline $^{3}$} \\
\hline British Columbia & 0.39 & 0.19 & 0.02 & 0.07 & 0.01 \\
\hline Alberta & 4.43 & 0.20 & 0.23 & 0.05 & 2.33 \\
\hline Saskatchewan & 1.52 & 0.08 & 0.15 & 0.02 & 4.95 \\
\hline Manitoba & 0.85 & 0.10 & 0.34 & 0.03 & 1.08 \\
\hline Ontario & 0.70 & 0.98 & 0.41 & 0.19 & 0.18 \\
\hline Quebec & 0.32 & 0.92 & 0.49 & 0.12 & 0.05 \\
\hline Atlantic & 0.09 & 0.15 & 0.04 & 0.03 & 0.02 \\
\hline \multirow[t]{2}{*}{ Canada } & 8.30 & 2.63 & 1.68 & 0.51 & 8.61 \\
\hline & \multicolumn{5}{|c|}{ Heating fuel $^{4}$} \\
\hline British Columbia & 0.22 & 0.11 & 0.02 & 0.40 & 0.01 \\
\hline Alberta & 2.53 & 0.11 & 0.35 & 0.28 & 1.37 \\
\hline Saskatchewan & 0.87 & 0.04 & 0.24 & 0.10 & 2.92 \\
\hline Manitoba & 0.49 & 0.06 & 0.53 & 0.20 & 0.64 \\
\hline Ontario & 0.40 & 0.54 & 0.64 & 1.12 & 0.10 \\
\hline Quebec & 0.18 & 0.51 & 0.77 & 0.72 & 0.03 \\
\hline Atlantic & 0.05 & 0.08 & 0.07 & 0.18 & 0.01 \\
\hline Canada & 4.75 & 1.45 & 2.62 & 2.99 & 5.08 \\
\hline
\end{tabular}

\footnotetext{
11996 Farm energy use survey for Canada

${ }^{2}$ Grains and oil seed farms

${ }^{3}$ gasoline purchased by farm operators for farm-owned vehicles.

${ }^{4}$ includes fumace-oil, liquid propane (LPG) and natural gas
}

Table 1. The provincial 2001 energy quantities for the three energy terms and the farm types identified at a national scale in the FEUS'.

The analysis for this chapter did not disaggregate provincial livestock populations directly into the CARs. Instead, it was the LCC areas defined by these populations that were 
disaggregated at this scale. Like the NLR area summations, only crop records for those crops that were in each respective livestock diet were summed within the CARs, rather than the areas from all crop records in the CEEMA database. The basis for identifying these crop records was the set of provincial LCC calculations for each livestock type provided by Vergé et al. (2012).

Since the FEUS data were collected in 1996 and the CEEMA data were derived from the 2001 agricultural census, the energy quantities in Figure 1 had to be indexed from 1996 to 2001. This was done by factoring the 1996 energy terms by the ratio of the respective size of each farm system from the 2001 census records to the size of the same farm system in the 1996 census records. Updating from 1996 to 2001 was done at the same time as the farm type energy quantities from the FEUS were disaggregated to the provinces, as shown in Table 1. The different farm types required different definitions of size. For the four livestock farm types, these provincial size ratios were of total livestock weights from the two years, whereas for grain and oilseed farm areas (NLR), these provincial ratios were of total crop production (planted areas times yields) from the two census years.

\subsection{Area allocation to each CAR}

The allocation of LCC areas (A) to each CAR for each livestock type was determined by the aggregate share of all feed crops in the provincial LCC in that CAR. Crop areas from the crop records were converted to area totals in each CAR for each of the 12 LCC crops (listed above) that were common to both the CEEMA database and to the four LCCs (Vergé et al., 2012). The total LCC areas in the crop records (Dyer et al., 2011b) were integrated to the respective CARs for each livestock type. The allocation to livestock types was based on the share of each of the four LCCs in each province, which were derived from the diet of each livestock population (Vergé et al., 2012).

For ruminant livestock, the allocation of provincial energy quantities to the CARs required a means of equating the dietary contribution of roughages with that of feed grains. For ruminants, $1.8 \mathrm{~kg}$ of roughages provide the same nutrient energy as $1 \mathrm{~kg}$ of feed grains (IFAS, 1998; Neel, 2012; Schoenian, 2011). Using this ratio, the forages in the respective LCC areas were converted to the equivalent feed grains on the basis of crop production estimates derived from the 2001 census crop yields. This general relationship also applies to pulses and oilseed meals, but ignores the protein contributions from those feeds. This relationship is altered slightly for corn silage which provides only $42 \%$ by weight of the nutrient value of other roughages (Miller and Morrison, 1950). Rangeland was excluded because there were no available data for farm energy consumption associated with this form of land use. Very little energy would be consumed to manage rangeland because no fertilizer or chemical inputs are used and, normally, there are no farm field operations.

In addition to the different nutritional values, the bulk yield differences between grains $(g)$ and roughages $(r)$ also account for the importance of these two crop group areas in each LCC. For each CAR the total LCC area $\left(\mathrm{A}_{C A R}\right)$ was the result of the two areas $\left(\mathrm{A}_{C A R, g}\right.$ and $\left.\mathrm{A}_{C A R, r}\right)$. Each area was weighted by the average total production weights for the crop group 
(F) within each provincial LCC and 1.8 (the nutritional value ratio for $g$ and $r$ ). This weighted area total was calculated for each CAR as follows.

$$
\mathrm{A}_{\mathrm{CAR}}=\left(\left(\mathrm{A}_{\mathrm{CAR}, \mathrm{g}} \times \mathrm{F}_{\mathrm{g}}\right)+\left(\mathrm{A}_{\mathrm{CAR}, \mathrm{r}} \times \mathrm{F}_{\mathrm{r}} / 1.8\right)\right) /\left(\mathrm{F}_{\mathrm{g}}+\left(\mathrm{F}_{\mathrm{r}} / 1.8\right)\right)
$$

These LCC area calculations at the CAR level were integrated over each province as follows.

$$
\mathrm{A}_{\text {prov }}=\sum^{\mathrm{CAR}} \mathrm{A}_{\mathrm{CAR}}
$$

Each energy term (E) from the FEUS for each province (Equation 1) was then disaggregated from the province to the CAR level as follows.

$$
\mathrm{E}_{\mathrm{CAR}}=\mathrm{E}_{\text {prov }} \times\left(\mathrm{A}_{\mathrm{CAR}} / \mathrm{A}_{\text {prov }}\right)
$$

Dyer et al. (2011b) found that occasionally the amounts of some crops were too low to meet the dietary needs of the provincial livestock populations. Because of these crop deficits, production from the surplus provinces had to be transported to the deficit provinces. Due to the reduction of $A_{C A R, r}$ by $1 / 1.8$ and the occasional accumulation of these provincial crop deficits and surpluses, $\mathrm{A}_{C A R}$ was an indexed area estimate which did not equal the actual total LCC area for the CAR. Without reducing $\mathrm{A}_{C A R, r}$ by $55 \%, \mathrm{~A}_{\text {prov }}$ would have the same difference with the provincial LCC area total (prior to these deficit corrections) as each $\mathrm{A}_{C A R}$ would have with the CAR total of the LCC area. Thus, using the CAR to province area ratios of these two weighted area estimates to disaggregate provincial energy terms does not result in any unnecessary distortion of the CAR energy estimates compared to the CAR-province ratios of uncorrected LCC areas.

The usefulness of disaggregating to the CAR scale depends on the sensitivity of the farm energy terms to land use parameters. Since the goal of this chapter was to determine the spatial distribution of the farm energy budget, a sensitivity analysis based on purely management-based range tests such as those described by Dyer and Desjardins (2003a) would not adequately demonstrate the sensitivity of farm energy terms to the factors that determine the spatial distribution of farm energy use at the CAR scale. This was because the only available spatial parameter at the sub-provincial CAR scale was the array of crop areas from CEEMA. Instead, the spatial sensitivity was equated to the variance of energy estimates across CARs in each province. Such sensitivity would reveal the impacts of local crop choice decisions on the consumption of different energy types. 


\section{Results and discussion}

\subsection{Farm energy budget at the CAR scale}

The basic output from the analysis described in this chapter was the set of disaggregated farm energy terms at the CAR scale. Due to the extent of these data, they are presented in appendices, rather than as tabular results in the main body of the chapter. Some care is needed in the numbering system in these appendices since the website maps for two provinces use a different CAR numbering system than was used in CEEMA. For Manitoba, CEEMA CAR number 1 includes the online map numbers 1, 2 and 3; CEEMA number 2 includes the online map numbers 4, 5 and 6; and CEEMA number 5 includes the online map numbers 9 and 10. For CEEMA numbers 3, 4 and 6, the online map numbers are 7, 8 and 11, respectively. The online map number 12 was not used in CEEMA. To be consistent with the online CAR base map, the 10 CEEMA CARs for Ontario were combined into 5 CARs in the two Appendices.

The data presented in Appendix A are preliminary to the general (non-commodity-specific) farm energy budget in Appendix B. They resulted from the need to use farm types to disaggregate the FEUS data. The data presented in Appendix B are the intended output or primary goal of this chapter. These data represent all six terms in the energy budget described by Dyer and Desjardins (2009). The data for the three energy terms extracted from the FEUS in Appendix B were derived by integrating the data in Appendix A over the five farm types. Although it is difficult to extract any trends from these data arrays by inspection that could not otherwise be seen from provincial scale tables, these two appendices make the data at the CAR scale available for future regional investigations in farm energy use in Canada.

\subsection{Provincial farm energy}

Table 2 presents a re-integration of the spatially detailed data in Appendix B from the CAR to provincial scale. Even given the limited spatial detail of this table, it still puts all terms of the Canadian farm energy budget into one source, based on one integrated methodology. Not surprisingly, given its large crop area, Saskatchewan was the biggest consumer of all forms of farm energy in Canada. This was most evident in the farm machinery-related terms, which likely reflects the extensive grains and oilseeds farming system in that province. The two coastal regions (British Columbia and the Atlantic Provinces), as well as Quebec and Ontario, contribute much less to the farm energy budget than the three Prairie Provinces, simply because of the much smaller areas in agricultural use. Although fertilizers (and other farm chemicals) are the largest cause of energy consumption, the farm machinery-related terms combined are $9 \%$ higher, nationally, than the chemical inputs. The three FEUS-based terms, to which so much attention was devoted in this chapter, account for only $20 \%$ of the national farm energy budget. 


\begin{tabular}{|c|c|c|c|c|c|c|}
\hline & $\begin{array}{c}\text { Farm } \\
\text { field work }\end{array}$ & $\begin{array}{c}\text { Machinery } \\
\text { supply }\end{array}$ & $\begin{array}{c}\text { Chemical } \\
\text { inputs }\end{array}$ & $\begin{array}{l}\text { Electric } \\
\text { power }\end{array}$ & Gasoline $^{1}$ & $\begin{array}{l}\text { Heating } \\
\text { fuel }^{2}\end{array}$ \\
\hline Provinces & & & $\mathrm{P}$ & & & \\
\hline British Columbia & 1.1 & 0.6 & 1.0 & 0.6 & 0.7 & 0.8 \\
\hline Alberta & 19.4 & 11.1 & 34.8 & 3.1 & 7.2 & 4.6 \\
\hline Saskatchewan & 31.7 & 18.2 & 35.3 & 2.5 & 6.7 & 4.2 \\
\hline Manitoba & 10.6 & 6.1 & 21.3 & 1.4 & 2.4 & 1.9 \\
\hline Ontario & 8.6 & 4.9 & 11.1 & 2.6 & 2.5 & 2.8 \\
\hline Quebec & 4.7 & 2.7 & 6.5 & 2.3 & 1.9 & 2.2 \\
\hline Atlantic & 0.9 & 0.5 & 1.4 & 0.4 & 0.3 & 0.4 \\
\hline Canada & 76.9 & 44.1 & 111.4 & 12.9 & 21.7 & 16.9 \\
\hline
\end{tabular}

\footnotetext{
${ }^{1}$ Gasoline purchased by farm operators for farm-owned vehicles.

${ }^{2}$ Includes fumace-oil, liquid propane (LPG) and natural gas
}

Table 2. Provincial estimates of the six energy terms of the Canadian farm energy budget during 2001.

\subsection{Assessing sensitivity through spatial variance}

The spatial variance assessments of the spatial data in this chapter are shown in Tables 3 and 4 . The statistic used to compare spatial variance was the coefficient of variation (CV) of the CAR energy values within each province. Being the ratio of standard deviations to their respective means, the CVs give a normalized, and thus a comparable, measure of spatial variability. In order to avoid the CVs being affected by the sizes of the CARs, the data in the two appendices were converted to energy intensities using areas of arable land extracted from the CEEMA crop records (discussed in more detail below). To illustrate, if the disaggregated energy intensities are evenly dispersed across all CARs in the province, then the crop records in the CEEMA database would have no impact on the distribution of energy consumption. Evenly dispersed energy quantities across all CARs would also result in no variance among the CARs and a provincial CV of zero.

Table 3 presents the CVs for the data presented in Appendix A, while Table 4 presents the CVs for Appendix B. In Table 3, only one set of CV estimates was needed for all three energy terms since there was no source of spatial variation associated with these energy terms prior to disaggregation to the CARs. For the pork, poultry and grains and oilseeds farm types, the two coastal provinces had the highest CVs in Table 3. Manitoba had the lowest CVs for these three farm types, which were also the lowest CVs in Table 3. For dairy, Quebec had the lowest CV, while for beef, the lowest CV was in Alberta. The poultry industry had the highest spatial variation, followed by grains and oilseeds, while dairy had the lowest overall spatial variation. Spatial variation for pork and poultry was lowest in the Manitoba. The spatial variations for pork and poultry were generally higher than for beef and dairy. On average, the Prairies had lower CVs than the other provinces. All of the CVs in Table 3 were higher than zero and there were appreciable differences among these CVs. 
Hence, the crops that drive these five farming systems were not evenly distributed among the CARs.

\begin{tabular}{|c|c|c|c|c|c|}
\hline \multirow[b]{2}{*}{ Provinces } & Beef & Dairy & Pork & Poultry & $\mathrm{G}_{\mathrm{OOS}}^{3}$ \\
\hline & \multicolumn{5}{|c|}{$\mathrm{CV}^{4}$} \\
\hline British Columbia & 0.31 & 0.30 & 0.84 & 1.27 & 0.90 \\
\hline Alberta & 0.25 & 0.18 & 0.34 & 0.33 & 0.39 \\
\hline Saskatchewan & 0.35 & 0.25 & 0.30 & 0.26 & 0.27 \\
\hline Manitoba & 0.39 & 0.27 & 0.19 & 0.18 & 0.16 \\
\hline Ontario & 0.53 & 0.20 & 0.38 & 0.40 & 0.13 \\
\hline Quebec & 0.30 & 0.13 & 0.65 & 0.65 & 0.38 \\
\hline Atlantic & 0.39 & 0.32 & 0.83 & 1.01 & 0.82 \\
\hline \multicolumn{6}{|l|}{${ }^{1}$ Farm energy use survey } \\
\hline \multicolumn{6}{|c|}{${ }^{2}$ census agricultural regions of Canada } \\
\hline \multicolumn{6}{|l|}{${ }^{3}$ grains and oils farms } \\
\hline${ }^{4}$ these $\mathrm{CV}$ estimates rep & hree en & from th & & & \\
\hline
\end{tabular}

Table 3. Provincial Coefficients of Variation (CV) for the disaggregation of energy use by five farm types from the FEUS 1 to the CARs $^{2}$ during 2001.

Whereas there were no spatial differences among the three energy terms from the FEUS when they were separated by their farm types (Table 3), integrating over those five farm types in Table 4 created some differences among these three energy terms. Since farm field work and machinery supply were connected to each other through the F4E2 model, and had the same spatial variations, only the farm field work CVs were shown in Table 4. Farm field work, electric power and gasoline use all had similar CVs which were all lower than the CVs for heating fuels and chemical inputs. The higher CVs for heating fuels likely reflect the combining of three fuel types into one term.

Manitoba had the lowest average CV over the five energy terms in Table 4. British Columbia had the highest CVs for all energy terms except chemical inputs, which were highest in Saskatchewan. The Atlantic Provinces and then Quebec had the next highest CVs after British Columbia. The CV for electric power in Ontario was so low that it suggested almost no spatial differences for this term in Ontario. There was not as much within-province variation among the energy terms (Table 4) as among the farm types (Table 3) that determined the spatial variations for three of those terms. The CVs in Table 4 still display an appreciable amount of within-province spatial variation, however.

The more hilly and ecologically-varied terrain in the coastal provinces may account for some of the spatial variance in British Columbia and the Atlantic Provinces compared to the prairies. However, the agricultural areas in the Prairie Provinces, particularly Saskatchewan, are greater than in the other provinces, and have a greater range in latitude, and hence climate, 
which would result in higher spatial variation among the CARs. In spite of the relatively low CVs in some cases, Tables 3 and 4 still suggest that the data presented in the two appendices can provide some guidance on where in each province farm energy use would be the highest or the lowest for each energy term.

\begin{tabular}{cccccc}
\hline & $\begin{array}{c}\text { Farm } \\
\text { field work }\end{array}$ & $\begin{array}{c}\text { Chemical } \\
\text { inputs }\end{array}$ & $\begin{array}{c}\text { Electrical } \\
\text { power }\end{array}$ & Gasoline & $\begin{array}{c}\text { Heating } \\
\text { fuel }\end{array}$ \\
\cline { 2 - 6 } Provinces & & & CV & & \\
\hline British Columbia & 0.32 & 0.33 & 0.47 & 0.34 & 0.70 \\
Alberta & 0.20 & 0.26 & 0.12 & 0.12 & 0.11 \\
Saskatchewan & 0.07 & 0.44 & 0.16 & 0.17 & 0.16 \\
Manitoba & 0.08 & 0.22 & 0.14 & 0.13 & 0.12 \\
Ontario & 0.11 & 0.16 & 0.02 & 0.13 & 0.14 \\
Quebec & 0.25 & 0.11 & 0.16 & 0.08 & 0.34 \\
Atlantic & 0.25 & 0.28 & 0.23 & 0.20 & 0.45 \\
\hline
\end{tabular}

${ }^{1}$ census agricultural regions of Canada

Table 4. Provincial Coefficients of Variation (CV) for the disaggregation of the six energy terms in the Canadian farm energy budget to the CARs ${ }^{1}$ during 2001.

\subsection{Fossil $\mathrm{CO}_{2}$ emissions from farm energy use}

To satisfy the secondary goal of this chapter the farm energy budget presented in Table 2 was converted to fossil $\mathrm{CO}_{2}$ emissions. With the variety of energy types that are used in Canadian agriculture, a different conversion was required for each of the six energy terms. For the diesel fuel for field work, coal to manufacture steel for farm machinery and gasoline,

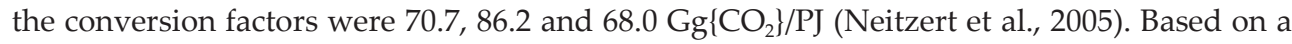
summary of fertilizers manufacturing energy dynamics by Nagy (2001), Dyer and Desjardins (2007) used $57.9 \mathrm{Gg}\left\{\mathrm{CO}_{2}\right\} / \mathrm{PJ}$ as the conversion factor for fossil $\mathrm{CO}_{2}$ emissions from fertilizer supply. Even though the chemical input supply energy computations were driven by just nitrogen applications, this conversion took into account all three fertilizers, not just nitrogen, since all three fertilizers were included in this energy term. Reasoning that a very small additional share of the input energy was devoted to the supply of pesticides, which were not included in the calculations from Nagy (2001), Dyer and Desjardins (2009) defined this $\mathrm{CO}_{2}$ emissions term as chemical inputs, rather than fertilizer supply.

Because heating fuel includes three separate fossil fuels, $\mathrm{CO}_{2}$ emission rates had to be determined for each farm type in the same way as energy consumption rates for heating fuel were determined. This was done by converting the set of fuel and farm type estimates for this energy term and converting them to $\mathrm{CO}_{2}$ emissions, using 59.8, 61.0 and 67.7 $\mathrm{Gg}\left\{\mathrm{CO}_{2}\right\} / \mathrm{PJ}$, for LPG, natural-gas and furnace-oil (Neitzert et al., 2005). The conversion factor for each fuel and farm type was the ratio of these $\mathrm{CO}_{2}$ emissions and the previously discussed energy consumption amounts. The blended factors had only minor variation among 
the provinces, however, ranging from $61.8 \mathrm{Gg}\left\{\mathrm{CO}_{2}\right\} / \mathrm{PJ}$ for Saskatchewan to $66.6 \mathrm{Gg}\left\{\mathrm{CO}_{2}\right\} / \mathrm{PJ}$ for the Atlantic Provinces. Therefore, the average heating fuel conversion factor for Canada, 64.1 $\mathrm{Gg}\left\{\mathrm{CO}_{2}\right\} / \mathrm{PJ}$, was used for all provinces in Table 5.

Since they were interested in a national farm energy budget, Dyer and Desjardins (2009) used a single average conversion factor for $\mathrm{CO}_{2}$ emissions for the consumption of electric power. Their factor allowed for $22 \%$ of Canadian electricity generation being from coal-fired plants. However, there are great differences among provinces in the dependence of coalbased generation (NRCan, 2005), ranging from $96 \%$ in Alberta to 0\% in Quebec. Because of the goal of provincial disaggregation of all farm fossil $\mathrm{CO}_{2}$ emissions to provinces in this chapter, the conversion factor for each province was computed separately using the provincial percent of coal generation from each province. The resulting conversion factors were 41.4, 264.8, 209.6, 2.8, 44.1, 0.0 and $162.4 \mathrm{Gg}\left\{\mathrm{CO}_{2}\right\} / \mathrm{PJ}$, respectively, for British Columbia, Alberta, Saskatchewan, Manitoba, Ontario, Quebec and the Atlantic Provinces.

\begin{tabular}{|c|c|c|c|c|c|c|}
\hline & $\begin{array}{c}\text { Farm } \\
\text { field work }\end{array}$ & $\begin{array}{c}\text { Machinery } \\
\text { supply }\end{array}$ & $\begin{array}{c}\text { Chemical } \\
\text { inputs }\end{array}$ & $\begin{array}{l}\text { Electric } \\
\text { power }\end{array}$ & Gasoline $^{1}$ & $\begin{array}{c}\text { Heating } \\
\text { fuel }^{2}\end{array}$ \\
\hline Provinces & \multicolumn{6}{|c|}{$\mathrm{Gg} \mathrm{CO}_{2}$} \\
\hline British Columbia & 79 & 55 & 61 & 23 & 46 & 49 \\
\hline Alberta & 1,372 & 961 & 2,014 & 832 & 492 & 295 \\
\hline Saskatchewan & 2,238 & 1,567 & 2,044 & 533 & 457 & 258 \\
\hline Manitoba & 749 & 524 & 1,231 & 4 & 163 & 122 \\
\hline Ontario & 605 & 423 & 643 & 114 & 167 & 183 \\
\hline Quebec & 332 & 233 & 378 & 0 & 130 & 145 \\
\hline Atlantic & 60 & 42 & 81 & 59 & 23 & 26 \\
\hline Canada & 5,435 & 3,805 & 6,451 & 1,566 & 1,478 & 1,078 \\
\hline
\end{tabular}

Table 5. Provincial fossil $\mathrm{CO}_{2}$ emissions from the six terms of the Canadian farm energy budget during 2001.

Like Table 2, the provincial differences in Table 5 reflect the range in sizes of the agriculture sector in the provinces. Saskatchewan accounted $36 \%$ of the fossil $\mathrm{CO}_{2}$ emissions, while the three Prairie Provinces accounted for $80 \%$. The two coastal provinces only accounted for $4 \%$. While fertilizer supply was the largest energy term, the two terms related to farm field work exceeded fertilizer supply as a $\mathrm{CO}_{2}$ emitter by $50 \%$. Heating fuels had the lowest emissions, both for Canada and for all of the provinces. The three terms from the FEUS emitted only $21 \%$ of the fossil $\mathrm{CO}_{2}$ from Canadian agriculture. The greatest variation among provinces was from the electric power term, due to the provincial differences in the use of coal for generating power. Heating fuels showed the least variation among provinces.

With a few minor adjustments to methodology, the basic energy budget described in this chapter (prior to spatial disaggregation) was very similar to the national energy budget pre- 
sented by Dyer and Desjardins (2009). Therefore, the total emissions for Canada in Table 5 can be compared to the $\mathrm{CO}_{2}$ totals for 2001 in that paper. Dyer and Desjardins (2009) showed higher $\mathrm{CO}_{2}$ emissions for gasoline and heating fuels than this chapter because that analysis included several horticultural farm systems that were not included in the CEEMA database. Electric power $\mathrm{CO}_{2}$ emissions were higher in this chapter than the emissions from this term by Dyer and Desjardins (2009). This was due to the decision to use province-specific energy to $\mathrm{CO}_{2}$ conversions for electric power generation in this chapter, which captured the greater dependence on coal in the provinces with the largest agriculture sectors. The national $\mathrm{CO}_{2}$ emissions estimate for three energy terms that could be computed directly from the CEEMA crop records in this chapter were all equal to the 2001 estimates reported by Dyer and Desjardins (2009).

\subsection{Energy use and $\mathrm{CO}_{2}$ emission intensities}

The farm fossil fuel associated with feedstock production would depend on the specific type of feedstock crop to be produced. The data in Appendix B provide a set of baseline data against which the fossil fuel required for a specific feedstock crop choice would have to be compared. These data represent the mean quantities of farm energy used either for food or livestock feed production in each CAR. These mean energy quantities, summarized by province in Table 2 and converted to $\mathrm{CO}_{2}$ emissions in Table 5, were also converted to the area based intensities shown in Figure 2 using the crop areas presented in Table 6. These areas include annual crops and seeded perennial forages summarized from the CEEMA crop records to the CAR scale. The CARs in Table 6 are numbered in the same sequence that was used in the two appendices. Because the areas in unseeded pasture and other marginal lands account for almost no farm energy use in Canada, they were not included in Table 6. These data can be used with Appendix B to calculate the intensity of energy use in each CAR (and were used in Tables 3 and 4). Over $80 \%$ of the arable land in Canada is in the three Prairie Provinces, and almost half of Canada's farmland is in Saskatchewan.

Figure 2 integrates the six energy terms in each province. Figure 2a shows the mean energy use per ha while Figure $2 \mathrm{~b}$ shows the mean $\mathrm{CO}_{2}$ emissions per ha. Although the distribution of $\mathrm{CO}_{2}$ emissions resembles the distribution of energy uses across the provinces, there are slight differences because of the different farm type mixes and fuel types associated with those farm types among the provinces. Saskatchewan had the lowest energy use and $\mathrm{CO}_{2}$ emission intensities because that province has the lowest share of its arable land devoted to livestock feed.

The following example illustrates how to reconcile biofuel feedstock production with farm fuel use and fossil $\mathrm{CO}_{2}$ emissions. Using their 2009 methodology, Dyer and Desjardins (2007) described theoretical $\mathrm{CO}_{2}$ emission budgets for a wheat farm in Saskatchewan and a dairy farm in Ontario. From the perspective of carbon footprint, the simulated wheat farm would be similar to a farm growing grain as a feedstock for ethanol. Based solely on fossil $\mathrm{CO}_{2}$ emissions, the emission intensity for the ethanol feedstock crop was only $0.26 \mathrm{t} / \mathrm{ha}$, compared to the mean intensity of $0.49 \mathrm{t} / \mathrm{ha}$ for all farm types in Saskatchewan in Figure 2b. This 
result suggests that diverting farmland to grow ethanol feedstock might actually lower the average on-farm fossil $\mathrm{CO}_{2}$ emissions in Saskatchewan.

\begin{tabular}{|c|c|c|c|c|c|c|c|}
\hline \multirow{3}{*}{$\begin{array}{c}\text { CAR } \\
\#\end{array}$} & \multicolumn{7}{|c|}{ Provinces } \\
\hline & British & & & & & & Atlantic \\
\hline & Columbia & Alberta & Saskatchewan & Manitoba & Ontario & Quebec & Provinces \\
\hline & \multicolumn{7}{|c|}{ ha, 000} \\
\hline 1 & 11 & 766 & 1,252 & 1,413 & 822 & 182 & 113 \\
\hline 2 & 22 & 1,036 & 1,351 & 750 & 1,083 & 94 & 128 \\
\hline 3 & 27 & 940 & 2,198 & 665 & 373 & 45 & 90 \\
\hline 4 & 17 & 1,993 & 733 & 781 & 624 & 73 & 6 \\
\hline 5 & 65 & 1,107 & 2,108 & 397 & 444 & 102 & \\
\hline 6 & 2 & 974 & 2,196 & 505 & & 97 & \\
\hline 7 & 57 & 1,513 & 1,342 & & & 116 & \\
\hline 8 & 185 & & 1,569 & & & 84 & \\
\hline 9 & & & 1,849 & & & 210 & \\
\hline 10 & & & & & & 472 & \\
\hline 11 & & & & & & 219 & \\
\hline Total & 386 & 8,329 & 14,598 & 4,511 & 3,347 & 1,695 & 337 \\
\hline
\end{tabular}

Table 6. Areas in annual crop and seeded perennial forges distributed over the 55 Cencus Agricultural Region (CAR) of Canada during 2001.

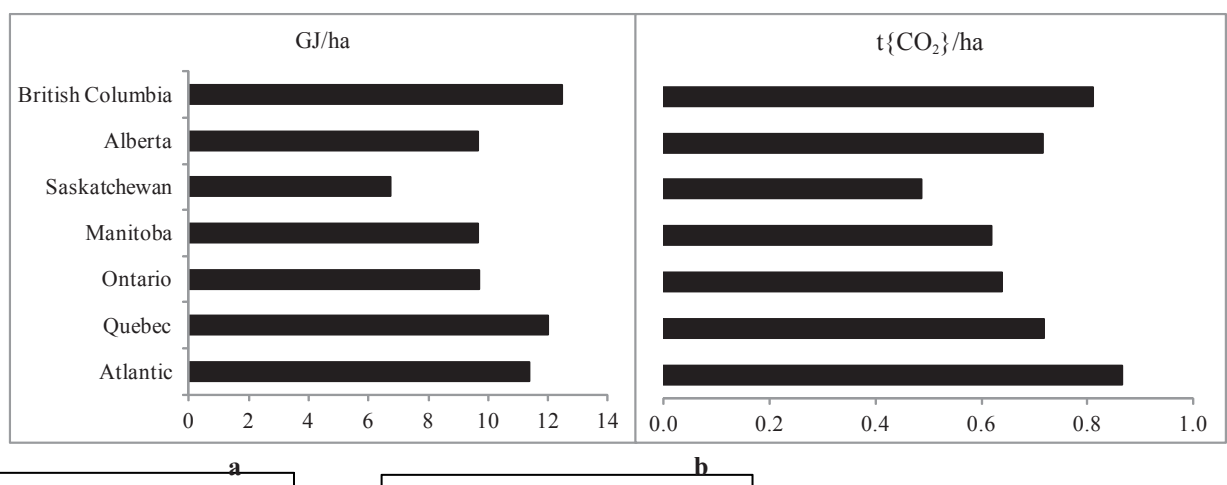

Figure 2. Area based intensity of on-farm energy use (a) and fossil $\mathrm{CO}_{2}$ emissions (b) from all farm types in each province of Canada in 2001.

In Ontario, the simulated dairy farm emission intensity described by Dyer and Desjardins (2007) was $0.62 \mathrm{t} / \mathrm{ha}$, compared to the $0.64 \mathrm{t} / \mathrm{ha}$ for all farm types in the province. This close agreement reflects the high share of Ontario farmland that is devoted to livestock production, much of which is dairy. These comparisons ignore $\mathrm{CO}_{2}$ emissions from the soil, as well as the other types of GHG. A similar comparison would also be possible for the energy required to grow other biofuel feedstock crops based on data presented in this chapter. Since it 
is often debatable what the correct land base should be when comparing per ha intensities of different farm types, Figure 2 should be viewed with caution. Farm land has a wide range of capabilities and intensities of use. Therefore the efficiency of food or feedstock production is not necessarily determined by land use intensity.

\section{Summary and conclusions}

Quantifying the local impacts from land use changes driven by expanding markets for biofuel was a major focus in this chapter. The degree of spatial detail for the complete farm energy budget presented here is unprecedented in Canada. The sensitivity analysis technique for farm energy demonstrated by Dyer and Desjardins (2003a) could be used to assess scenarios for the growth of biofuel industries. While this has been done for livestock to biofuel feedstock interactions in Canada (Dyer et al., 2011c), more detailed spatial resolution for such scenario or sensitivity analysis is required. With the three Prairie Provinces accounting for $80 \%$ of both the arable land and overall farm energy use in Canada (Tables 2 and 6), the ability to assess the energy consumption patterns in this region in more spatial detail than at the provincial scale is especially important. The procedure described in this chapter disaggregated all terms to the CAR scale before re-integrating to the provincial scale. Because of this quantitative link with the CARs, and its computational flexibility, this procedure is ideally suited to this sensitivity analysis application.

\subsection{Limitations of the study}

The energy budget presented in this chapter does not represent all of the farm energy provided by the FEUS. This was because only those farming systems that are extensive users of farmland are relevant to the regional focus of CEEMA. The excluded energy consumers, including the horticultural enterprises such as market gardeners, fruit growers and greenhouses, are typically clustered within a few highly favourable climate zones, usually in proximity to population centres. In addition, relative to total agricultural energy use, these enterprises are very small and, consequently, small users of energy. In spite of the CEEMA data being derived from economic analysis, while the previous farm energy budget described by Dyer and Desjardins (2009) used actual crop statistics as input data, there was close agreement between these two sets of energy use estimates.

It should be cautioned that the farm energy budget described in this chapter will undergo changes, particularly since it applied to 2001. There are both uncertainties and on-going trends in several of the energy terms in this budget. The most dramatic case has been the impact of reduced tillage on farm use of diesel fuel for field operations (Dyer and Desjardins, 2005). An increasing popularity of diesel fuel for farm owned transport vehicles may mean that some use of diesel fuel for tasks other than field operations may have to be monitored and taken into account in future farm energy budget estimates. The fossil $\mathrm{CO}_{2}$ emissions that can be attributed to farm use of electric power could also change as coal generating plants are replaced by natural gas, nuclear reactors, or renewable power sources. 
For example, natural gas, with its lower $\mathrm{CO}_{2}$ to energy ratio than coal, is becoming increasingly available for this purpose (NEB, 2006).

There are also suggestions that ammonia-based nitrogen fertilizers could consume less natural gas than other forms of this chemical input (CAP, 2008) and that allowance for increased use of ammonia-based nitrogen fertilizer is needed in the carbon footprint of farm operations. However, the estimates of $\mathrm{CO}_{2}$ emissions associated with the supply of farm chemical inputs by Dyer and Desjardins (2009), upon which this chapter was based, is consistent with, if not lower than, other studies. For example, over the four census years prior to 2001, the average national $\mathrm{CO}_{2}$ emissions for chemical inputs reported by Dyer and Desjardins (2009) was $9 \%$ below the same period average fossil $\mathrm{CO}_{2}$ emissions for this term by Janzen et al. (1999). Snyder et al. (2007) reported $\mathrm{CO}_{2}$ to $\mathrm{N}$ conversion rates that were the same as the $4.05 \mathrm{t}\left\{\mathrm{CO}_{2}\right\} / \mathrm{t}\{\mathrm{N}\}$ conversion used by Dyer and Desjardins (2009) for Nebraska and $10 \%$ higher for Michigan.

The assumption that most farm animals are located near their feed sources was essential to the disaggregation of the three empirical energy terms. This assumption was sound for cattle as roughage makes up an important part of their diet and, except for drought years, its long-distance transport is uneconomic. This assumption was somewhat less sound for pork and poultry as feed grains (including oilseed meal) are more easily transported. Nevertheless, for these livestock types there is an advantage to having production near the cropland that provides the feed and is available for manure disposal. The higher spatial variation for the pork and poultry compared to beef and dairy in Table 3 would support the impact of this advantage. Although pork and poultry were the smallest of the five farming systems, and the three empirical energy terms were also the smallest terms, it would be worthwhile to gather data on the distances over which livestock farmers can cost-effectively ship feed grains. Furthermore, a reliable estimate of the energy used by farmers for transport would be essential to an objective carbon footprint comparison of livestock farming with biofuel feedstock production.

\subsection{Going forward: Implications for biofuels}

Trends in farm energy levels will also reflect shifts in land use towards feedstock for biofuels. Providing farm type-specific energy data in Appendix A with this chapter identified the energy quantities that are most likely to shift as land resources are reallocated from livestock or food crops into feedstock if the biofuel market opportunities expand. Because of the uncertainties in the farm energy budget, such as more efficient manufacturing of farm inputs, and the land use challenges associated with the emerging biofuel industries, flexibility will be needed. The examples provided here with Figure 2 demonstrated how changes in land use can affect the area based intensity of farm energy consumption and fossil $\mathrm{CO}_{2}$ emissions. Hence, the analytical procedures for farm energy described in this chapter are being maintained in a dynamic, integrated and repeatable computation procedure. With this flexibility it can facilitate revisions in the Canadian farm energy budget or shifts in farm management as predicted in an updated version of the CEEMA. 
This chapter devoted relatively more space and effort to the electric power, gasoline and heating fuel terms than to the field work and two supply terms. Although the three terms from the FEUS were smaller energy quantities, there were two reasons for this extra attention. First, they have received almost no analysis, at least from a modeling perspective, prior this analysis. Consequently, the disaggregation of these terms was much more interpolative than process based. Second, the different levels of use by the five major farm types in Canada of these energy sources, combined with the regional differences in where these farming systems are most often found, resulted in the appreciable spatial variations at the CAR scale shown in Table 3, at least compared to Table 4.

The liquid fossil fuels burned in farm-owned vehicles (both gasoline and diesel) warrants more rigorous treatment because of its overlap with the question of the energy costs of transporting food products to processors and consumers, or feedstock to biofuel plants. Development of a predictive model for this term will depend on better understanding of how and where producers market their produce and the extent to which processers are involved in the collection of that produce, whether it is milk, wheat or canola oil. This is particularly true for biofuel feedstock where the haulage cost can grow in comparison to the production cost if the processing plants are not strategically located. Optimizing the locations of biofuel processing sites will depend on the knowledge of both energy uses and the spatial distribution of land use systems.

Much of the farm energy budget presented in this chapter was based on the 1996 FEUS. Including verification of the F4E2 model, five of the six terms in this energy budget were derived from this database. Updating the FEUS would also facilitate disaggregation of the later years in the farm fossil $\mathrm{CO}_{2}$ emissions budget described by Dyer and Desjardins (2009) to both the provinces and the CARS. The importance of farm energy in the GHG emissions budget for both agriculture and biofuels requires a repeat of the 1996 FEUS. Since the FEUS entailed survey methodology, rather than actual measurements, an updated FEUS would be an expensive undertaking in Canada. Whereas electric power showed some promise for a predictive tool (Dyer and Desjardins, 2006b), the other FEUS-based terms, gasoline and heating fuels, offer little hope of being worked into a predictive model, although they could be indexed to changing livestock populations. Fortunately, all three of these terms contribute relatively little to Canada's farm energy budget compared to the other three terms.

Growth in biofuel industries is driving the crop selections by many Canadian farmers towards feedstock crops. But as global population expands, major land use shifts will also occur in the food industries, such as from beef or pork production, to more grains and pulses for direct human consumption. Food industries that are now minor, such as vegetable production, may see dramatic growth in response to both food demand and to a warmer climate. Canadian agriculture may well be challenged by shortages of fossil fuel to do field work and commercial fertilizer. The CEEMA database also needs to be updated to help meet these challenges. Until a repetition of the FEUS is undertaken, updated regional farm energy use, and fossil $\mathrm{CO}_{2}$ emission estimates using more recent census 
years and an up to date version of CEEMA, will help to fill the information gaps caused by looming changes in the sector.

\section{Appendix A}

\begin{tabular}{|c|c|c|c|c|c|c|c|c|c|c|c|c|c|c|c|c|}
\hline \multirow[b]{3}{*}{ Provinces } & \multirow{3}{*}{$\begin{array}{c}\text { CAR } \\
\#\end{array}$} & \multicolumn{3}{|c|}{ Beef } & \multicolumn{3}{|c|}{ Dairy } & \multicolumn{3}{|c|}{ Pork } & \multicolumn{3}{|c|}{ Poultry } & \multicolumn{3}{|c|}{ G\&OS } \\
\hline & & $\mathrm{EP}$ & Gas & $\mathrm{HF}$ & EP & Gas & $\mathrm{HF}$ & EP & Gas & $\mathrm{HF}$ & $\mathrm{EP}$ & Gas & $\mathrm{HF}$ & $\mathrm{EP}$ & Gas & $\mathrm{HF}$ \\
\hline & & & & & & & & & $\mathrm{TJ}$ & & & & & & & \\
\hline \multirow[t]{8}{*}{ British Columbia } & 1 & 5 & 12 & 7 & 5 & 4 & 2 & 0 & 0 & 0 & 0 & 0 & 1 & 0 & 0 & 0 \\
\hline & 2 & 9 & 24 & 13 & 10 & 7 & 4 & 0 & 0 & 0 & 2 & 1 & 7 & 0 & 0 & 0 \\
\hline & 3 & 20 & 52 & 30 & 23 & 18 & 10 & 3 & 2 & 3 & 28 & 14 & 80 & 0 & 0 & 0 \\
\hline & 4 & 9 & 23 & 13 & 12 & 9 & 5 & 1 & 1 & 1 & 4 & 2 & 11 & 0 & 0 & 0 \\
\hline & 5 & 26 & 67 & 39 & 28 & 22 & 12 & 1 & 1 & 1 & 4 & 2 & 10 & 0 & 0 & 0 \\
\hline & 6 & 1 & 2 & 1 & 1 & 1 & 0 & 0 & 0 & 0 & 0 & 0 & 1 & 0 & 0 & 0 \\
\hline & 7 & 20 & 51 & 29 & 26 & 20 & 11 & 1 & 1 & 2 & 5 & 2 & 14 & 0 & 1 & 0 \\
\hline & 8 & 60 & 156 & 89 & 145 & 111 & 62 & 16 & 11 & 17 & 99 & 47 & 277 & 3 & 10 & 6 \\
\hline \multirow[t]{7}{*}{ Alberta } & 1 & 134 & 347 & 198 & 19 & 15 & 8 & 30 & 21 & 33 & 9 & 4 & 25 & 85 & 263 & 155 \\
\hline & 2 & 178 & 462 & 264 & 39 & 30 & 16 & 66 & 46 & 72 & 19 & 9 & 53 & 161 & 499 & 294 \\
\hline & 3 & 199 & 517 & 295 & 34 & 26 & 15 & 37 & 26 & 40 & 10 & 5 & 27 & 75 & 232 & 137 \\
\hline & 4 & 358 & 928 & 531 & 60 & 46 & 26 & 88 & 62 & 96 & 28 & 13 & 78 & 197 & 611 & 360 \\
\hline & 5 & 288 & 746 & 426 & 39 & 30 & 17 & 34 & 24 & 37 & 10 & 5 & 28 & 72 & 223 & 131 \\
\hline & 6 & 298 & 772 & 441 & 33 & 25 & 14 & 22 & 15 & 24 & 6 & 3 & 18 & 48 & 148 & 87 \\
\hline & 7 & 255 & 662 & 378 & 35 & 27 & 15 & 46 & 32 & 50 & 17 & 8 & 47 & 114 & 354 & 208 \\
\hline \multirow[t]{9}{*}{ Saskatchewan } & 1 & 53 & 139 & 79 & 9 & 7 & 4 & 18 & 13 & 20 & 3 & 2 & 9 & 127 & 394 & 232 \\
\hline & 2 & 31 & 79 & 45 & 6 & 5 & 3 & 14 & 10 & 15 & 2 & 1 & 7 & 268 & 437 & 258 \\
\hline & 3 & 92 & 239 & 136 & 11 & 9 & 5 & 19 & 13 & 20 & 4 & 2 & 10 & 252 & 780 & 460 \\
\hline & 4 & 39 & 100 & 57 & 5 & 4 & 2 & 6 & 5 & 7 & 1 & 1 & 3 & 127 & 394 & 232 \\
\hline & 5 & 93 & 242 & 138 & 17 & 13 & 7 & 40 & 28 & 43 & 6 & 3 & 18 & 234 & 726 & 428 \\
\hline & 6 & 69 & 180 & 103 & 14 & 11 & 6 & 35 & 25 & 39 & 6 & 3 & 17 & 234 & 725 & 428 \\
\hline & 7 & 34 & 87 & 50 & 9 & 7 & 4 & 22 & 16 & 25 & 4 & 2 & 11 & 163 & 507 & 299 \\
\hline & 8 & 51 & 133 & 76 & 12 & 9 & 5 & 30 & 21 & 33 & 5 & 2 & 14 & 179 & 556 & 328 \\
\hline & 9 & 124 & 322 & 184 & 19 & 15 & 8 & 35 & 25 & 38 & 5 & 3 & 15 & 198 & 615 & 362 \\
\hline \multirow[t]{6}{*}{ Manitoba } & 1 & 91 & 235 & 135 & 45 & 35 & 19 & 194 & 136 & 212 & 27 & 13 & 75 & 122 & 380 & 224 \\
\hline & 2 & 74 & 191 & 109 & 26 & 20 & 11 & 78 & 54 & 85 & 13 & 6 & 36 & 58 & 181 & 107 \\
\hline & 3 & 40 & 105 & 60 & 15 & 12 & 6 & 61 & 43 & 67 & 10 & 5 & 28 & 52 & 161 & 95 \\
\hline & 4 & 28 & 71 & 41 & 14 & 10 & 6 & 66 & 47 & 73 & 12 & 6 & 33 & 62 & 191 & 113 \\
\hline & 5 & 36 & 92 & 53 & 12 & 9 & 5 & 39 & 27 & 42 & 5 & 3 & 15 & 26 & 82 & 48 \\
\hline & 6 & 61 & 159 & 91 & 20 & 15 & 8 & 44 & 31 & 48 & 6 & 3 & 16 & 27 & 82 & 48 \\
\hline \multirow[t]{5}{*}{ Ontario } & 1 & 97 & 250 & 143 & 371 & 285 & 158 & 93 & 65 & 102 & 67 & 32 & 187 & 14 & 42 & 25 \\
\hline & 2 & 81 & 211 & 120 & 397 & 305 & 169 & 191 & 134 & 209 & 131 & 63 & 367 & 20 & 61 & 36 \\
\hline & 3 & 19 & 50 & 29 & 123 & 95 & 52 & 86 & 60 & 94 & 56 & 27 & 158 & 7 & 21 & 12 \\
\hline & 4 & 17 & 44 & 25 & 182 & 140 & 77 & 164 & 114 & 179 & 116 & 55 & 324 & 11 & 35 & 21 \\
\hline & 5 & 55 & 143 & 82 & 208 & 160 & 88 & 50 & 35 & 55 & 31 & 15 & 86 & 6 & 18 & 11 \\
\hline \multirow[t]{11}{*}{ Quebec } & 1 & 16 & 40 & 23 & 134 & 103 & 57 & 27 & 19 & 30 & 10 & 5 & 29 & 3 & 9 & 5 \\
\hline & 2 & 7 & 18 & 10 & 67 & 52 & 29 & 16 & 11 & 18 & 4 & 2 & 11 & 2 & 6 & 4 \\
\hline & 3 & 4 & 10 & 6 & 34 & 26 & 14 & 13 & 9 & 14 & 6 & 3 & 16 & 1 & 2 & 1 \\
\hline & 4 & 5 & 12 & 7 & 48 & 37 & 20 & 38 & 26 & 41 & 15 & 7 & 42 & 1 & 3 & 2 \\
\hline & 5 & 12 & 30 & 17 & 89 & 68 & 38 & 17 & 12 & 18 & 6 & 3 & 18 & 1 & 2 & 1 \\
\hline & 6 & 5 & 12 & 7 & 59 & 45 & 25 & 59 & 41 & 65 & 21 & 10 & 58 & 1 & 3 & 2 \\
\hline & 7 & 12 & 31 & 18 & 97 & 75 & 41 & 31 & 22 & 34 & 12 & 6 & 33 & 1 & 3 & 2 \\
\hline & 8 & 9 & 23 & 13 & 69 & 53 & 29 & 8 & 6 & 9 & 3 & 1 & 8 & 1 & 3 & 2 \\
\hline & 9 & 21 & 54 & 31 & 168 & 129 & 71 & 42 & 30 & 46 & 16 & 8 & 44 & 2 & 6 & 4 \\
\hline & 10 & 20 & 52 & 30 & 280 & 215 & 119 & 352 & 246 & 385 & 129 & 62 & 361 & 3 & 10 & 6 \\
\hline & 11 & 15 & 39 & 22 & 152 & 117 & 65 & 101 & 70 & 110 & 34 & 17 & 96 & 2 & 6 & 4 \\
\hline \multirow[t]{4}{*}{ Atlantic provinces } & 1 & 12 & 31 & 18 & 63 & 48 & 27 & 9 & 6 & 10 & 4 & 2 & 12 & 2 & 6 & 3 \\
\hline & 2 & 9 & 24 & 13 & 59 & 45 & 25 & 35 & 24 & 38 & 35 & 17 & 97 & 3 & 10 & 6 \\
\hline & 3 & 12 & 31 & 18 & 72 & 55 & 31 & 20 & 14 & 22 & 24 & 11 & 67 & 1 & 2 & 1 \\
\hline & 4 & 1 & 3 & 2 & 5 & 4 & 2 & 0 & 0 & 0 & 0 & 0 & 0 & 0 & 0 & 0 \\
\hline
\end{tabular}

Table 7. The 2001 energy quantities for Electrical Power (EP), Gasoline (Gas) and Heating Fuels (HF) distributed over five farm types and the 55 Census Agricultural Regions (CAR) of Canada 


\section{Appendix B}

\begin{tabular}{|c|c|c|c|c|c|c|c|}
\hline \multirow[b]{2}{*}{ Provinces } & \multirow{2}{*}{$\begin{array}{c}\text { CAR } \\
\#\end{array}$} & $\begin{array}{c}\text { Farm } \\
\text { field work }\end{array}$ & $\begin{array}{c}\text { Machinery } \\
\text { supply }\end{array}$ & $\begin{array}{l}\text { Chemical } \\
\text { inputs }\end{array}$ & $\begin{array}{c}\text { Electrical } \\
\text { power }\end{array}$ & Gasoline & $\begin{array}{l}\text { Heating } \\
\text { fuels }\end{array}$ \\
\hline & & \multicolumn{6}{|c|}{$\mathrm{TJ}$} \\
\hline \multirow[t]{8}{*}{ British Columbia } & 1 & 28 & 16 & 34 & 10 & 17 & 11 \\
\hline & 2 & 60 & 34 & 66 & 21 & 32 & 25 \\
\hline & 3 & 124 & 71 & 145 & 74 & 86 & 122 \\
\hline & 4 & 51 & 30 & 65 & 26 & 35 & 31 \\
\hline & 5 & 137 & 78 & 178 & 59 & 92 & 62 \\
\hline & 6 & 4 & 2 & 6 & 2 & 3 & 2 \\
\hline & 7 & 102 & 58 & 120 & 52 & 75 & 56 \\
\hline & 8 & 608 & 349 & 433 & 323 & 336 & 451 \\
\hline \multirow{7}{*}{ Alberta } & 1 & 1,908 & 1,095 & 1,935 & 277 & 650 & 419 \\
\hline & 2 & 3,532 & 2,028 & 5,095 & 463 & 1,047 & 700 \\
\hline & 3 & 2,133 & 1,224 & 3,637 & 355 & 806 & 514 \\
\hline & 4 & 4,182 & 2,401 & 7,448 & 731 & 1,660 & 1,090 \\
\hline & 5 & 2,594 & 1,489 & 6,622 & 443 & 1,027 & 639 \\
\hline & 6 & 1,923 & 1,104 & 4,469 & 407 & 964 & 584 \\
\hline & 7 & 3,139 & 1,802 & 5,582 & 467 & 1,082 & 699 \\
\hline \multirow[t]{9}{*}{ Saskatchewan } & 1 & 2,461 & 1,413 & 2,531 & 211 & 553 & 345 \\
\hline & 2 & 2,835 & 1,627 & 2,231 & 321 & 532 & 328 \\
\hline & 3 & 4,926 & 2,828 & 2,978 & 377 & 1,042 & 632 \\
\hline & 4 & 1,608 & 923 & 859 & 178 & 502 & 301 \\
\hline & 5 & 4,925 & 2,827 & 7,523 & 391 & 1,012 & 635 \\
\hline & 6 & 4,227 & 2,427 & 4,139 & 359 & 944 & 593 \\
\hline & 7 & 2,958 & 1,698 & 2,556 & 232 & 618 & 387 \\
\hline & 8 & 3,649 & 2,095 & 5,394 & 278 & 722 & 456 \\
\hline & 9 & 4,073 & 2,338 & 7,088 & 382 & 978 & 608 \\
\hline \multirow[t]{6}{*}{ Manitoba } & 1 & 3,288 & 1,887 & 6,916 & 479 & 798 & 665 \\
\hline & 2 & 1,659 & 952 & 3,785 & 248 & 452 & 347 \\
\hline & 3 & 1,650 & 947 & 2,751 & 179 & 325 & 256 \\
\hline & 4 & 1,945 & 1,116 & 2,761 & 181 & 325 & 265 \\
\hline & 5 & 1,005 & 577 & 2,641 & 118 & 213 & 163 \\
\hline & 6 & 1,051 & 603 & 2,407 & 158 & 290 & 212 \\
\hline \multirow[t]{5}{*}{ Ontario } & 1 & 1,892 & 1,086 & 3,128 & 642 & 675 & 615 \\
\hline & 2 & 2,850 & 1,636 & 3,678 & 820 & 774 & 902 \\
\hline & 3 & 1,106 & 635 & 1,110 & 292 & 253 & 345 \\
\hline & 4 & 1,697 & 974 & 1,579 & 490 & 389 & 626 \\
\hline & 5 & 1,011 & 580 & 1,605 & 350 & 371 & 322 \\
\hline \multirow[t]{11}{*}{ Quebec } & 1 & 365 & 210 & 571 & 190 & 176 & 144 \\
\hline & 2 & 225 & 129 & 297 & 96 & 89 & 71 \\
\hline & 3 & 109 & 63 & 163 & 56 & 49 & 50 \\
\hline & 4 & 216 & 124 & 266 & 106 & 85 & 112 \\
\hline & 5 & 204 & 117 & 462 & 124 & 116 & 92 \\
\hline & 6 & 341 & 196 & 366 & 144 & 111 & 156 \\
\hline & 7 & 262 & 151 & 495 & 153 & 136 & 128 \\
\hline & 8 & 151 & 87 & 306 & 90 & 86 & 61 \\
\hline & 9 & 446 & 256 & 854 & 249 & 226 & 196 \\
\hline & 10 & 1,749 & 1,004 & 1,871 & 785 & 586 & 901 \\
\hline & 11 & 634 & 364 & 874 & 304 & 249 & 297 \\
\hline \multirow[t]{4}{*}{ Atlantic provinces } & 1 & 277 & 159 & 482 & 90 & 93 & 69 \\
\hline & 2 & 402 & 231 & 440 & 141 & 120 & 180 \\
\hline & 3 & 162 & 93 & 439 & 128 & 113 & 138 \\
\hline & 4 & 11 & 7 & 37 & 6 & 7 & 4 \\
\hline
\end{tabular}

${ }^{1}$ Include furnace oil, liquid propane (LPG) and natural gas

Table 8. Energy quantities in the six terms of the Canadian farm energy balance distributed over 55 Census Agricultural Regions (CAR) of Canada during 2001. 


\section{Author details}

J.A. Dyer ${ }^{1}$, R.L. Desjardins², B.G. McConkey ${ }^{3}$, S. Kulshreshtha ${ }^{4}$ and X.P.C. Vergé ${ }^{5}$

1 Agro-environmental Consultant, Cambridge, Ontario, Canada

2 Agriculture \& Agri-Food Canada, Ottawa, Canada

3 Agriculture \& Agri-Food Canada, Swift Current, Canada

4 University of Saskatchewan, Saskatoon, Canada

5 Agro-environmental Consultant to AAFC, Ottawa, Ontario, Canada

\section{References}

[1] AAFC, 2011. Soil Landscapes of Canada (SLC), General Overview. Agriculture and Agri-food Canada (AAFC). http://sis.agr.gc.ca/cansis/nsdb/slc/intro.html. Accessed 7 May 2012.

[2] Dyer, J.A. and R.L. Desjardins. 2003a. The impact of farm machinery management on the greenhouse gas emissions from Canadian agriculture. Journal of Sustainable Agriculture. 20(3):59-74.

[3] Dyer, J.A. and R.L. Desjardins. 2003b. Simulated farm fieldwork, energy consumption and related greenhouse gas emissions in Canada. Biosystems Engineering 85(4): 503-513.

[4] Dyer, J.A. and R.L. Desjardins. 2005. Analysis of trends in CO2 emissions from fossil fuel use for farm fieldwork related to harvesting annual crops and hay, changing tillage practices and reduced summerfallow in Canada. Journal of Sustainable Agriculture. 25(3):141-156.

[5] Dyer, J.A. and R.L. Desjardins. 2005. Analysis of trends in $\mathrm{CO} 2$ emissions from fossil fuel use for farm fieldwork related to harvesting annual crops and hay, changing tillage practices and reduced summerfallow in Canada. Journal of Sustainable Agriculture. 25(3):141-156.

[6] Dyer, J.A. and R.L. Desjardins. 2006a. Carbon dioxide emissions associated with the manufacturing of tractors and farm machinery in Canada. Biosystems Engineering. 93(1):107-118.

[7] Dyer, J.A. and R.L. Desjardins, 2006b. An integrated index for electrical energy use in Canadian agriculture with implications for greenhouse gas emissions. Biosystems Engineering. 95(3):449-460. 
[8] Dyer,J. A. and R. L. Desjardins. 2007. Energy-based GHG emissions from Canadian Agriculture. Journal of the Energy Institute. 80(2):93-95.

[9] Dyer, J.A. and R.L. Desjardins. 2009. A review and evaluation of fossil energy and carbon dioxide emissions in Canadian agriculture. Journal of Sustainable Agriculture 33(2):210-228.

[10] Dyer, J.A., X.P.C. Vergé, R.L. Desjardins, D.E. Worth, B.G. McConkey. 2010a. The impact of increased biodiesel production on the greenhouse gas emissions from field crops in Canada. Energy for Sustainable Development 14(2):73-82.

[11] Dyer, J.A., S.N. Kulshreshtha, B.G. McConkey and R.L. Desjardins. 2010b. An assessment of fossil fuel energy use and $\mathrm{CO}_{2}$ emissions from farm field operations using a regional level crop and land use database for Canada. Energy 35(5):2261-2269.

[12] Dyer, J.A. O.Q. Hendrickson, R.L. Desjardins and H.L. Andrachuk. 2011a. An Environmental Impact Assessment of Biofuel Feedstock Production on Agro-Ecosystem Biodiversity in Canada. In: Agricultural Policies: New Developments. Chapter 3:87-115. Editor: Laura M. Contreras, ISBN 978-1-61209-630-8. Nova Science Publishers Inc. Hauppauge, NY 11788. 281 pp.

[13] Dyer, J.A., X.P.C. Vergé, S.N. Kulshreshtha, R.L. Desjardins, and B.G. McConkey. 2011b. Residual crop areas and greenhouse gas emissions from feed and fodder crops that were not used in Canadian livestock production in 2001. Journal of Sustainable Agriculture 35(7):780-803.

[14] Dyer, J.A., X.P.C. Vergé, R.L. Desjardins and B.G. McConkey. 2011c. Implications of biofuel feedstock crops for the livestock feed industry in Canada. In: Environmental Impact of Biofuels. Chapter 9, pages 161-178, Editor: Marco Aurelio Dos Santos Bernardes. InTech Open Access Publisher. Rijeka, Croatia. September 2011, ISBN 978-953-307-479-5. 270 pp.

[15] CAP, 2008. Benchmark energy efficiency and carbon dioxide emissions. Canadian Ammonia Producers (CAP).Office of Energy Efficiency, Natural Resources Canada. Ottawa, Canada. ISBN 978-0-662-46150-0, Cat. No. M144-155/2007E-PDF. 34pp.

[16] GAO, 2009. Biofuels - Potential effects and challenges of required increases in production and use. Report to Congressional Requesters. United States Government Accountability Office (GAO). August 2009. GAO-09-446. 184 pp.

[17] Horner, G.L., J. Gorman, R.E. Howett, C.A. Carter and R.J. MacGregor. 1992. The Canadian regional agricultural model: structure, operation and development. Policy Branch. Technical Report 1/92. Ottawa. Agriculture and Agri-food Canada. http:www.agr.gc.ca/pol/index_e.php?s1=pub\&s2=visions\&page=v_pt2.

[18] IFAS, 1998. Replacing hay with grain. Chapter 6, The Disaster Handbook - 1998 Edition. Institute of Food and Agricultural Sciences, Cooperative Extension Service, University of Florida. 
[19] Janzen, H.H., R.L. Desjardins, J.M.R. Asselin and B. Grace (Editors). 1999. The Health of our Air - Towards Sustainable Agriculture in Canada. Agriculture and Agri-food Canada. Publ. No. 1981 E. ISBN 0-662-27170-X, 105 pp.

[20] Klein, K.K., LeRoy, D.G. 2007. The Biofuels Frenzy: What's in it for Canadian Agriculture? Green Paper Prepared for the Alberta Institute of Agrologists. Presented at the Annual Conference of Alberta Institute of Agrologists. Banff, Alberta, March 28, 2007. Department of Economics, University of Lethbridge. 46 pp.

[21] Kulshreshtha, S.N. .B. Jenkins, R.L. Desjardins and J.C. Giraldez. 2000. A systems approach to estimation of greenhouse gas emissions from the Canadian agriculture and agri-food sector. World Resources Review. 12:321-337.

[22] Malcolm, S. and M. Aillery. 2009. Growing crops for biofuels has spillover effects. Amber Waves 7(1):10-15. March issue.

[23] Miller, J. I. and F. B. Morrison, 1950. Comparative Value of Mixed Hay and Corn Silage for Wintering Beef Cows. Journal of Animal Science. 9(2):243-247. http:// jas.fass.org/content/9/2/243.abstract

[24] Nagy, C.N. 2000. Energy and greenhouse gas coefficients inputs used in agriculture. Report to the Prairie Adaptation Research Collaborative (PARC). The Canadian Agricultural Energy End-use Data and Analysis Centre (CAEEDAC) and the Centre for Studies in Agriculture, Law and the Environment (CSALE).

[25] NEB, 2006. Natural gas for power generation: issues and implications. ISBN 0-662-43472-2. Cat No. NE23-136/2006E. National Energy Board (NEB), Calgary, Alberta, Canada. 60pp. www.neb-one.gc.ca.

[26] Neitzert, F., K. Olsen and P. Collas, 1999. Canada's greenhouse gas inventory - 1997Emissions and removals with trends. Air Pollution Prevention Directorate, Environment Canada. Ottawa, Canada. ISBN 0-622-27783-X. Cat No. En49-8/5 9E. 160pp.

[27] Neel, James B. 2012. Rules of thumb for winter feeding. Animal Science Info Series: AS-B-260, University of Tennessee, Agricultural Extension Service. http://animalscience.ag.utk.edu/beef/pdf/RulesOfThumb.260.pdf. Accessed 18 June 2012.

[28] NRCan, 2005. Energy Efficiency Trends in Canada, 1990 and 1996 - 2003. Office of Energy Efficiency, Natural Resources Canada. Cat. No. M141-/2003. ISBN 0-662-68797-3, 64 pp.

[29] Schoenian, Susan, 2011. The truth about grain: Feeding grain to small ruminants. Small Ruminant Info Sheet, University of Maryland Extension. http://www.sheepandgoat.com/articles/graintruth.html. Accessed 6 February 2012. Accessed 18 June 2012.

[30] Snyder, C.S., T.W. Bruulsema and T.L. Jenzen, 2007. Greenhouse gas emission from cropping systems and the influence of fertilizer management. International Plant Research Institute, Norcross, Georgia, USA. 36 pp. 
[31] Statistics Canada, 2007, Census Agricultural Regions Boundary Files for the 2006 Census of Agriculture - Reference Guide. Catalogue no. 92-174-GIE. http://publications.gc.ca/collections/collection_2007/statcan/92-174-G/92-174-GIE2007000.pdf. Accessed 7 May 2012.

[32] Tremblay, V. 2000. The 1997 Farm Energy Use Survey - Statistical Results. Contract Report prepared for The Office of Energy Use Efficiency, Natural Resources Canada, Ottawa, Ontario, Canada, and The Farm Financial Programs Branch, Agriculture and Agri-Food Canada, Ottawa, Ontario, Canada.

[33] Vergé, X.P.C., Dyer, J.A., Desjardins, R.L. and Worth, D. 2007. Greenhouse gas emissions from the Canadian dairy industry during 2001. Agricultural Systems 94(3): 683-693.

[34] Vergé, X.P.C., Dyer, J.A., Desjardins, R.L. and Worth, D. 2008. Greenhouse gas emissions from the Canadian beef industry. Agricultural Systems 98(2):126-134.

[35] Vergé, X.P.C., Dyer, J.A., Desjardins, R.L. and Worth, D. 2009a. Greenhouse gas emissions from the Canadian pork industry. Livestock Science. 121:92-101.

[36] Vergé, X.P.C., Dyer, J.A., Desjardins, R.L. and Worth, D. 2009b. Long Term trends in greenhouse gas emissions from the Canadian poultry industry. Journal of Applied Poultry Research. 18: 210-222.

[37] Vergé X.P.C., D.E. Worth, J.A. Dyer, R.L. Desjardins, and B.G. McConkey. 2011. LCA of animal production. In Green Technologies in Food Production and Processing, ed. by Joyce I. Boye and Yves Arcand, 83-114. New York: Springer.

[38] Vergé, X.P.C., J.A. Dyer, D.E. Worth, W.N. Smith, R.L. Desjardins, and B.G. McConkey, 2012. A greenhouse gas and soil carbon model for estimating the carbon footprint of livestock production in Canada. Accepted in Animals.2:437-454 